\title{
Major helminth parasites of Camelus dromedarius in afar pastoral area of Ethiopia
}

\author{
A.H. Desta \\ Department of Animal Sciences, College of Agriculture, Shire Campus, Aksum University, Shire, Ethiopia \\ email: meryangieboy@gmail.com
}

(Received May 8, 2018; Accepted September 2, 2018)

\begin{abstract}
Camel internal parasites are among important camel health problems which are often affecting camel production and productivity. A cross-sectional study was carried out in camels to study the major helminth parasites in selected districts of Afar regional state of Ethiopia. Coprological examination and key informants interview were done to collect the required data in the study areas. Fecal sample was collected from a total of 384 camels and about $76.04 \%$ (292) were found to harbor at least one helminth parasite. According to the flotation and sedimentation techniques, Trichostrongyle egg (71.6\%) was found with higher prevalence followed by coccidia (69.9\%). In the mixed infestation, occurrence of two parasites together (31.9\%) was with higher prevalence and occurrence of five parasites together (4.4\%) was the lowest one. According to the key informants, the occurrence and transmission of these parasites is higher in the study areas due to aggregation of camels in the cross-border salt trade and mixing of camel herds at watering and feeding points. Furthermore, there was no adequate seasonal and programmed treatment due to drug shortage. Therefore, collaborative parasitic control and prevention measure and public education on modern camel husbandry should be delivered.
\end{abstract}

Keywords: Coccidian, Floatation, Mixed infestation, Trichostrongyle Available online at http://www.vetmedmosul.com

$$
\begin{aligned}
& \text { الديدان الرئيسية في الجمال Camelus dromedaries في منطقة باستورل في أثيوبيا } \\
& \text { انجسيوم هادش ديستا } \\
& \text { فرع علوم الحيو ان، كلية الزر اعة، جامعة أقصم، شيري، أثثوبيا }
\end{aligned}
$$

الخلاصة

تعتبر الطفيليات الداخلية للإبل من بين المشاكل الصحية الهامة في الإبل و التي غالباً ما تؤثر على إنتاج إنتاج الجمال وتكاثره. أجريت در استة

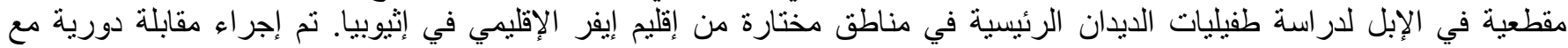

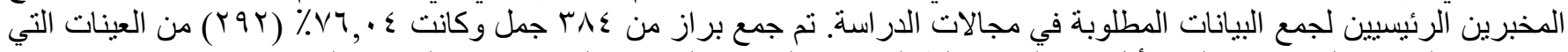

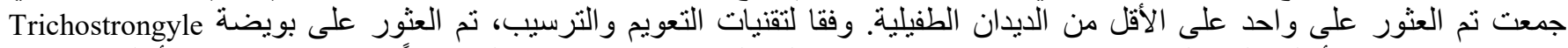

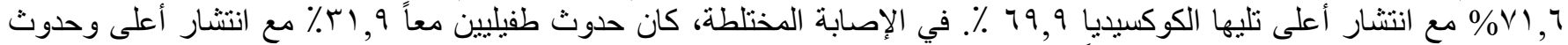

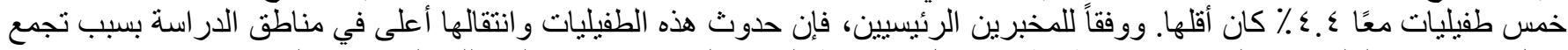

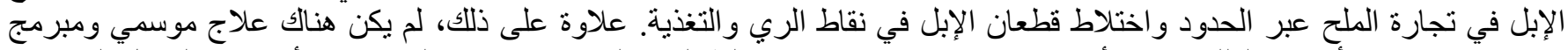

كافٍ بسبب نقص الأدوية. ولذلك، ينبخي أن يتم تنفيذ ندابير مكافحة ومنع الطفيليات التعاونية وتثقيف الجمهور بشأن تربية الجمال الحديثة.

\section{Introduction}

The one humped camel (Camelus dromedarius) are important domestic animal species that are well adapted to harsh environments and fluctuating nutritional conditions of extreme arid areas. These animals have extra ordinary features that enable them to survive and perform in harsh conditions (1). Dromedaries are versatile living assets that 
ensure food security and also serve as means of transportation and draught power in the pastoral areas $(2,3)$. Among the world, Africa hosts $80 \%$ population of dromedary in which $63 \%$ attributed to east Africa (4).

Camels are among the huge livestock resources in Ethiopia. It inhabits the arid and semi-arid areas of the country that constitute more than $60 \%$ of the total area and home for millions of pastoral and agro pastoral communities. The Eastern and Southern part of the country namely, Afar, Somalia and Borena are the major areas where camel husbandry is widely practiced. In this area, the livelihood of pastoral communities is certainly ensured by dromedaries (5).

The camels play an important role in the subsistence economy of the Ethiopian pastoral society by providing milk, meat and it is also as sole source of transportation as well as socio-cultural aspects such as prestige, compensation, dowry etc. Pathogenic diseases, poor nutrition and traditional management systems as well as lack of veterinary services have hampered their full utilization, despite the importance of dromedary in the semi-arid and arid areas where the environment is harsh and hostile (6).

Camel helminth parasites are among the important camel health problems which are often affecting camel production and productivity (7). Gastrointestinal helminthes cause losses through morbidity and hidden effects on feed intake, efficiency of nutrient utilization and growth rate of young animals. As a result, it leads to reduction in productivity and performance of the infested animal (6).

Helminthic infections of camels' gastrointestinal tract are classified into two groups as common and occasional. A number of helminths are camel specific, but some are also common to other hosts, especially domestic ruminants and wild animals (8). Camel specific nematodes are included; Haemonchus longisipes, Nematodirus Mauritanicus, Nematodirus dromedarii but most of camel nematodes are also common to sheep and goats, like Trichostrongylus prololurus, Tichostronglus vitrinus, Ostertagia mongolica, Nematodirus spathiger, Oesophagostomum venulosum Trichuris species, hydatid cysts (9). They inhabit the camel's intestines and can cause diarrhea. The cysts occur in the liver and lungs, can grow slowly and cause pressure on the organs that gradually increases causing injury from the inside (10).

Gastrointestinal parasites, may assume much more significant role in camel husbandry because parasites not only reduce the productivity and performance of camels but also predispose to other infectious diseases. Knowledge on camel husbandry management and parasitic diseases control is still very unreliable and insufficient (7). Therefore, the objectives of this study were to identify and determine the prevalence, types of parasitism and seasonal occurrence of major helminth parasites of camels in Afar pastoral area of Ethiopia.

\section{Material and methods}

\section{Description of study areas}

Afar regional state is located in the Great Rift Valley, comprising semi-arid range land in northeastern Ethiopia. According to regional estimates the livestock population of Afar is about 10.12 million TLU and out of this about $859,580(8.5 \%)$ are camels. The Afar Regional State has five administrative zones, which are further subdivided into 32 districts. Pastoralism and agro- pastoralism are the two major livelihood ways practiced in the region. The population of the region is estimated to be about 1.2 million of which $90 \%$ are pastoralists and $10 \%$ agro-pastoral. The altitude of the region ranges from $120 \mathrm{~m}$ below sea level to $1500 \mathrm{~m}$ above sea level. Temperatures vary from $20{ }^{\circ} \mathrm{C}$ in higher elevations to $48{ }^{\circ} \mathrm{C}$ in lower elevations. Rainfall is bi-modal throughout the region with a mean annual rainfall below $500 \mathrm{~mm}$ in the semi-arid western escarpments and decreasing to $150 \mathrm{~mm}$ in the arid zones to the east (11). The study was conducted in three purposively selected districts of two zones. Namely: Aba'ala and Berhale of Kilebeti Resu (zone two) and Dubti district of AwsiResu (zone one).

\section{Study population}

The approximate camel populations in Aba'ala, Berhale and Dubti districts are 28,834; 13,366 and 5966, respectively which were considered as study population (11). Individuals with age of 18 years and above were considered for the interview. The target group for the key informants interview were salt merchants, animal health professionals and camel owners.

\section{Study design}

A cross-sectional study design was conducted from September to January, 2016.

\section{Sampling methods and sample size}

Three districts were selected purposively; Aba'ala and Berhale due to the presence of camel movement cross border to other regions, line of salt trade and camel population and Dubti district due to easier accessibility. Pastoral association/PA is the lowest level of administration in the districts and there are 11 PAs (6 agro-pastoralists and 5 pastoralists) in Aba'ala, 9 PAs (6 agro-pastoralist and 3 pastoralists) in Berhale and 15 Pas (4 towns, 8 agropastoralists and 3 pastoralists) in Dubti district. About $30 \%$ of the PAs in each of the districts were considered representative to the district and included in the study on the basis of feasibility. Hence, four PAs from Aba'ala, three PAs from Berhale and five Pas from Dubti were selected randomly. 
Since there was no previous year's prevalence of major external and helminth parasitosis in the districts, the average expected prevalence was assumed to be $50 \%$ for the areas within 95\% Confidence Interval (CI) at 5\% desired accuracy and using the formula employed by Thrusfield (12) to calculate sample size (n) is as follows:

$\mathrm{n}=\frac{1.962 \times \mathrm{P}_{\mathrm{ex}}}{\mathrm{d}^{2}} \underline{\mathrm{x}}(1-\mathrm{P} \underline{\mathrm{ex}})$

Where $\mathrm{n}=$ sample size, $\mathrm{d}=$ desired absolute precision $(0.05), \mathrm{P}_{\mathrm{ex}}=$ expected prevalence $(50 \%)$, thus the desired sample size for $P_{e x}=0.5$ is $n=384$. A total of 384 camels were considered for the study. Based on their total camel population for each study districts, 230 samples were collected from Aba'ala, 106 samples from Berhale and 48 samples from Dubti districts. Demeke (13) reported the average herd size in the pastoralist area to be 14 animals, hence, $384 / 14 \approx 28$ herds are required. However, to increase sampling distribution level the number of herds is doubled to get the required sample size. Hence, a total of 56 $(28 \times 2)$ herds from three districts were considered and 34 camel herds from Aba'ala, 15 herds from Berhale and 7 herds from Dubti district were randomly selected according to their camel populations to get the required sample size. An individual camel from each randomly selected herd was sampled proportionally based on the number of camels found in that herd using the systematic random sampling technique on the spot. In addition, about 108 herd owners and salt merchants and around 32 animal health professionals in the health centers of the study areas were considered for the key informants interview.

\section{Study methodology and data collection Coprological examination}

Fecal samples were collected from the rectum of camels in the morning using plastic bottles for the presence of gastrointestinal parasite eggs. Fecal samples were collected during dry and wet/minor rainy seasons, respectively and stored at $4^{\circ} \mathrm{C}$ until laboratory analysis. A floatation and sedimentation technique were used to identify the eggs of helminth parasites. Morphological differentiation was based on microscopic appearance of the eggs encountered and compared to those in standard texts, micrographs and literatures. A sample collection format was also prepared and the history of the individual camels such as age, sex, body condition score and other characteristics were recorded while taking sample. The age of camels was classified as young (6 months - 4 years), adult (above 4 years) and body condition score of the camels during sampling was evaluated and categorized based on the characteristics set by Faye and Bengoumi (14). According to these authors, body condition score of dromedaries range from 5 (excellent) to 0 (very poor).

\section{Key informants interview}

Selected informants were interviewed about the camel husbandry and management practices and risk factors for occurrence and transmission of helminth parasites between and among camel herds.

\section{Data management and statistical analysis}

The data were summarized, compiled and after coding stored in Microsoft Excel 2007 spread sheet and transferred to SPSS ${ }^{\circledR}$ Version 20 for statistical analysis. Descriptive and analytic statistics was computed using software SPSS ${ }^{\circledR}$ Version 20. Logistic regression analysis was employed to see the association of risk factors with that of parasite infestation. The degree of association was computed using Odds Ratio (OR) and 95\% confidence interval (CI) (12).

\section{Results}

Fecal sample was collected from a total of 384 camels and about $76.04 \%(n=292)$ were found to harbor at least one helminth parasite. None of the risk factors considered has statistically significant association $(\mathrm{P}>0.05)$ with the parasitism according to the logistic regression analysis (Table 1).

According to the flotation and sedimentation techniques, Trichostrongyle egg $(71.6 \%)$ was found with higher prevalence followed by coccidia (69.9\%) (Table 2).

In the mixed infestation, occurrence of two parasites together $(31.9 \%)$ was with higher prevalence and occurrence of five parasites together (4.4\%) was the lowest one (Table 3).

\section{Key informants interview}

All of the respondents (100\%) said that camel helminth parasitism is a common problem on camel health and productivity in the study areas. They said that these conditions decrease the camel performance due to stress and other associated illness in the animal. According to the respondents, the risk factors for the parasitic infestation of camels are salt trade line between neighboring regions in Aba'ala and Berahle districts, mixing of camels at feeding and watering points, seasonal variation, poor husbandry and management practices. They also said once a camel is infested with parasites, it has a great chance to become diseased with other complications and infections.

All of the animal health professionals (100\%) said that the helminth parasitism has impacts on camel productivity and health. They also told that there are some drugs such as albendazole and ivermectin that helps to treat the camel parasitosis in the district clinics. However, there is drug shortage that hinders to undergo programmed and seasonal deworming in the areas. 
Table 1: Multivariable logistic regression analysis of risk factors with helminth parasitism

\begin{tabular}{lccccc}
\hline Risk factor & Category & No examined & Positive (\%) & OR (95\% CI) & P-value \\
\hline District & Aba'ala & 230 & $169(73.5)$ & - & \\
& Berahle & 106 & $84(79.2)$ & $1.58(0.72-3.48)$ & 0.25 \\
\multirow{5}{*}{ Sex } & Dubti & 48 & $39(81.2)$ & $1.13(0.47-2.71)$ & 0.78 \\
& Male & 132 & $104(78.8)$ & - & \\
Age & Female & 252 & $188(74.6)$ & $0.76(0.46-1.28)$ & 0.30 \\
& $\leq 4$ years & 161 & $119(73.9)$ & - & \\
Body condition score & >4 years & 223 & $173(77.6)$ & $1.23(0.76-1.98)$ & 0.40 \\
& Good & 75 & $58(77.4)$ & - & \\
& Fair & 197 & $152(77.2)$ & $0.75(0.37-1.50)$ & 0.41 \\
Season & Poor & 112 & $82(73.2)$ & $0.76(0.44-1.31)$ & 0.33 \\
& Dry & 192 & $141(73.4)$ & - & \\
& Rainy & 192 & $151(78.6)$ & $1.35(0.84-2.17)$ & 0.22 \\
\hline
\end{tabular}

Table 2: Prevalence of major camel helminth parasites in selected districts of Afar region

\begin{tabular}{|c|c|c|c|c|c|}
\hline \multirow[b]{2}{*}{ Parasites } & \multirow[b]{2}{*}{ Genera } & \multicolumn{2}{|c|}{ Season } & \multirow[b]{2}{*}{ Total } & \multirow[b]{2}{*}{ Prevalence $(\%)$} \\
\hline & & Dry & Rainy & & \\
\hline \multirow{5}{*}{ Nematodes } & Trichostrongylus & 97 & 112 & 209 & 71.6 \\
\hline & Strongyles & 87 & 95 & 182 & 62.3 \\
\hline & Strongloides & 41 & 30 & 71 & 24.3 \\
\hline & Nematodirus & 51 & 64 & 115 & 39.4 \\
\hline & Trichuris & 37 & 26 & 63 & 21.6 \\
\hline Trematode & Paramphystomum & 38 & 60 & 98 & 33.6 \\
\hline Cestode & Moniezia & 26 & 30 & 56 & 19.2 \\
\hline Protozoa & Coccidia & 89 & 115 & 204 & 69.9 \\
\hline
\end{tabular}

Table 3: Prevalence of camel helminth parasites with single and mixed infestation

\begin{tabular}{lcc}
\hline Infestation type & Parasites & Prevalence (\%) \\
\hline & Trichostrongylus & $37(12.8)$ \\
Single & Strongyles & $13(4.4)$ \\
& Nematodirus & $8(2.7)$ \\
& Paramphystomum & $5(1.7)$ \\
Mixed & Moniezia & $2(0.7)$ \\
& Coccidia & $28(9.6)$ \\
& Two parasites & $93(31.9)$ \\
& Three parasites & $57(19.5)$ \\
& Four parasites & $32(10.9)$ \\
\hline Total & Five parasites & $17(5.8)$ \\
\hline
\end{tabular}

\section{Discussion}

Fecal sample was collected from a total of 384 camels and about $292(76.04 \%)$ were found to harbor at least one helminth parasite. This overall prevalence of camel helminth parasites is in agreement with the findings of Borji et al. (7) and Anvari-Tafti et al. (15) in Iran, Bekele (6) in eastern Ethiopia, Mahmuda et al. (16) in Sokoto Nigeria and Kasahun et al. (17) in Yabello district of Ethiopia who reported $75.1 \%$ and $81.3 \%, 75 \%, 78 \%$ and $80.7 \%$, respectively. However, it is relatively lower than the reports of Sharif et al. (18) in Jordan, Tekle and Abede (19) in Borena Ethiopia, Aboma et al. (20) in camel slaughtered in Addis Ababa abattoir and Bamaiyi and Kalu (21) in Nigeria who reported $98 \%, 96.9 \%, 95.6 \%$ and $92.4 \%$, respectively. In contrast, it is greater than the prevalence report of Kamani et al. (22) who reported $68.9 \%$ in Nigeria. This variation in prevalence will be due to difference in season of sample collection, management and husbandry practices, agro-climatic conditions, accessibility to veterinary service and deworming programs in the areas $(17,23,24)$. In this study, a relatively higher prevalence of helminth parasites was recorded because of traditional husbandry practices, inaccessibility to veterinary services and inadequate seasonal and programmed deworming scheme in the areas.

District, sex, age, body condition and season of sample collection were the risk factors considered to assess the association with the occurrence of helminth parasites however according to the logistic regression analysis, none of the risk factors considered has statistically significant association $(\mathrm{P}>0.05)$ with the parasitism. This could be due to the relatively higher prevalence recorded in which a 
small figure difference between risk factor categories did not create significant association during analysis.

In this coprological study, about eight genera of internal parasites namely Trichostrongylus (71.6\%), Strongylus (62.3\%), Strongyloides (24.3\%), Nematodirus (39.4\%) and Trichuris (21.6\%) classified as Nematodes; Paramphystomum (33.6\%) classified as Trematode; Moniezia (19.2\%) classified as Cestode and Coccidia (69.9\%) classified as Protozoa were identified based on egg morphology.

According to this study, Trichostrongyle egg was found with higher prevalence which is in agreement with the finding of Kasahun et al (17). Out of the 292 infested camels, $78.8 \%$ were infested by Nematodes which is in agreement with the findings of Mahmuda et al (16) who reported $80.6 \%$ Nematode infestation. In addition, about $31.9 \%$ single infestation and $68.1 \%$ mixed infestation of two genera and above concurrently was recorded in this study. The single infestation is higher and the mixed infestation is lower than the reports recorded by different authors $(6,17,25,26)$. The impact of parasitic infestation on camel productivity and health are due to loss of appetite, body condition loss and emaciation, wasting disease, milk drop and stress. These conditions become serious especially in lactating she camels and young animals.

\section{Conclusion}

Relatively higher prevalence of camel helminth parasites was recorded in the study areas. The helminth parasites identified were majorly classified under nematodes having Trichostrongyle species with higher level of occurrence. Moreover, Paramphistomaum as Trematode, Moniezia as cestode and Coocidia as protozoa were identified as single and mixed infestation in the study areas. According to the key informants, the occurrence and transmission of parasites is higher in the study areas due to cross border salt trade and mixing of camel herds at watering and feeding points. In addition, there is loss of body condition, loss of production and complication with other infectious disease in the camels due to the parasitic infestation. There was no adequate seasonal and programmed treatment due to drug shortage. Therefore, prevention and control of parasites has to be done starting from the sources and vehicles of transmission of internal parasites, seasonal and programmed deworming schemes should be implemented and public education on modern camel husbandry and prevention of camel parasites should be provided.

\section{Acknowledgements}

The author would like to acknowledge Samara University for the research fund granted to this study and a special appreciation and gratitude goes to the Pastoral Agriculture and Rural development office of the study districts of Afar region for their valuable support in providing the required data and materials in need. Moreover, the author is grateful to animal health professionals of the districts for their support during sample collection.

\section{References}

1. Teka T. The dromedaries in eastern African countries. Nomad People. 1991;29:3-9.

2. Yagil R. The desert camel: Comparative physiological adaptation. Basel Karger.1985:163.

3. Higgins AJ, Allen WR, Mayhew IG, Snow DH Wade JF. An introduction to the camel in health and disease. In: Proceeding of the First International Camel Conference. R and W Publications Ltd: New Market, London;1992. p. 17-19.

4. Wilson FT. The Tropical Agriculturist. Camels. Macmillan Education Ltd. London;1998. p. 1-130.

5. Abebe D. Pastoralism and pastoral production system. In: Proceeding of the Ethiopian Society of Animal Production (ESAP). August 2000. Addis Ababa, Ethiopia;2000. p. 1-5.

6. Bekele T. Epidemiological studies on gastrointestinal helminthes of dromedary (Camelus dromedarius) in semi-arid lands of eastern Ethiopia. Vet Parasitol. 2002;105:139-52.

7. Borji H, Razmi G, Movassaghi AR, Naghibi AG, Maleki M. A study on gastrointestinal helminths of camels in Mashhad abattoir Iran. Iranian J Vet Res. 2010;11:174-179.

8. Wernery U, Kadden R. Infectious diseases in camelids. $2^{\text {nd }}$ ed. Berlin: Black well Science; 2002.

9. Banaja AA, Ghadour AM. A review of parasites of camels (Camelus dromedaries) in Saudi Arabia. J King Abdulaziz Univ Sci. 1994;6:7586.

10. Shawan W. Common intestinal parasite of camels. Vet Pet Health. 2011.

11. CSA (Central Statistical Agency). Human and animal population census in Ethiopia. Addis Ababa, Ethiopia; 2012.

12. Thrusfield M. Veterinary Epidemiology. $2^{\text {nd }}$ ed. London: Blackwell Science Ltd; 2005. 178-198 p.

13. Demeke G. Prevalence of camel trypanosomes and factors associated with the disease occurrence in Liben district, Borena Zone, Ethiopia [master's thesis]. Berlin: Free University of Berlin, Ethiopia; 1998.

14. Faye B, Bengoumi M. Assessment of body condition and body composition in camel by barymetric measurements. J Camel Prac Res. 2006;13:67-72.

15. Anvari-Tafti M, Sazmand AS, Hekmatimoghaddam S, Moobedi I. Gastrointestinal helminths of camels (Camelus dromedarius) in center of Iran. Trop Biomed. 2013;30(1):56-61.

16. Mahmuda A, Mohammed AA, Alayande MO, Habila YI, Lawal MD, Usman M, Raji AA, Saidu B, Yahaya MS, Suleiman N. Prevalence and distribution of gastrointestinal parasites of working camels in Sokoto metropolis. Vet World. 2014;7:108-112.

17. Kasahun D, Fikadu A, Ayalew N, Teka F. Prevalence of Gastrointestinal Parasites and Efficacy of Anthelmintics Against Nematodes in Camels in Yabello District, Southern Ethiopia. Acta Parasitol Glob. 2014;5(3):223-231. 
18. Sharrif L, Al-qudah KM, Al-Ani FK. Prevalence of gastrointestinal helminthes in one-humped camel in Jordan. J Camel Prac Res. 1997:41:67-69.

19. Tekle T, Abede G. Trypanosomosis and helminthoses: major health problems of camels (Camelus dromedarius) in the Southern Rangelands of Borena, Ethiopia. J Camel Prac Res. 2001;8(1):39-42.

20. Aboma R, Nesibu A, Birhanu H, Yisehak T, Teshale S. Internal and external parasites of camels (Camelus dromedarius) slaughtered at Addis Ababa Abattoir, Ethiopia. J Vet Med Anim Health. 2014;7(2):57-63.

21. Bamaiyi PH, Kalu AU. Gastrointestinal parasites infection in one humped camels of Nigeria. Vet Res Forum. 2011;2(4):278-281.

22. Kamani J, Turaki AU, Egwu GO, Mani AU, Kida SM, Abdullahi JG, Damina MS, Kumshe HA, Dogo GI. Prevalence of gastrointestinal parasites in camels (Camelus dromedaries) slaughtered in Maiduguri, Nigeria. J Camel Prac Res. 2008;15(2):181-182.

23. Allport R, Mosha RM, Bahari ES, Swai, Catley A. The use of community-based animal health workers to strengthen disease surveillance system in Tanzania. Rev sci tech Intern Office Epiz. 2005;24(3):921-932.

24. Mohamed A, Mahmoud MR, Abdella GA, El-Ella A. The influence of Some Nematode Parasitism on Lipid Metabolism and Lipoprotein Profile in Dromedary Camel. J Camel Sci. 2008;63-67.

25. Tembely S, Diarra PA, Waigalo Y. Preliminary observations on helminth parasite populations of the dromedary in northern Mali. Vet Parasitol. 1992;44(3-4):339-342.

26. Swai S, Moshy W, Mshanga D, Lutatina J, Bwanga S. Intestinal parasitic infections of camels in the agro and pastoral areas of northern Tanzania. Livest Res Rural Develop. 2011;23(5):115. 